\title{
Liquefaction Analysis Using Viscoplastic Kinematic Hardening Constitutive Model
}

\author{
T. Tanaka $\cdot$ K. Okajima
}

Received: 27 January 2008/Accepted: 20 October 2009/Published online: 31 December 2009

(C) The Author(s) 2009. This article is published with open access at Springerlink.com

\begin{abstract}
The dynamic response analysis combined with the generalized return-mapping algorithm is applied to the integration algorithms of viscoplastic constitutive relations including the effect of the shear band. The kinematic hardening model based on modified and extended soil model with isotropic strain-hardening-softening is employed. In this paper, the TESRA (temporary effect of strain rate and acceleration) model is employed for the nonlinear viscosity of sand. The constitutive equations of rate-dependent plasticity originally proposed by $\mathrm{Du}-$ vaut-Lions are employed as the base of the solutions. Liquefaction of a buried pipe is analyzed by finite element method by employing the above mentioned constitutive relations and the calculated results are compared with experimental results. The dynamic response analysis is applied to the solutions of the problems. The kinematic hardening-softening viscoplastic constitutive relations for geomaterials are promising for the predictions of cumulative deformations and liquefaction of the buried pipe. A great deal of experimental results indicate that the stress is a unique function of irreversible strain and its rate.
\end{abstract}

T. Tanaka $\cdot$ K. Okajima $(\bowtie)$

Department of Biological \& Environmental Engineering, University of Tokyo, Bunkyo-ku 1-1-1, Tokyo, Japan

e-mail: aokajim@mail.ecc.u-tokyo.ac.jp

T. Tanaka

e-mail: tad.tanaka@gmail.com
Keywords Plasticity - Kinematic hardening · Viscoplasticity · Dynamic relaxation . Return mapping

\section{Introduction}

In order to guarantee a mesh-objective consumption of energy, the strain softening modulus which is a function of element size, is made. This kind of shear banding model can incorporate a characteristic length of shear band in the material modeling based on physical and experimental observations of strain localization. The numerical simulation of the quasistatic deformations of geomaterials characterized by the viscoplastic constitutive model is of great significance and has been intensively studied in the past. Various viscoplastic material models have been proposed for the analysis of rate-dependent failure in geomaterials, shear banding and creep behavior. Among them, a widely used viscoplastic model is the Perzyna model (Perzyna 1966). This model is also known as the overstress model. The characteristics of the overstress model have been addressed by various authors (Simo et al. 1988; Simo and Hughes 1998). Simo et al. (1988) has pointed out that the Perzynatype models are, in general, not meaningful when the elastic domain is defined by several surfaces intersecting in a non-smooth fashion. 
In this paper, a viscoplastic jump kinematic hardening model of geomaterials is developed. This model is based on the modified and extended soil model of isotropic strain hardening and softening elasto-plastic constitutive equation. The constitutive model is applied to the boundary value problems such as cyclic behavior of geotechnical problems. The explicit type dynamic relaxation method (Tanaka and Kawamoto 1988) is used for the pseudo-static cyclic triaxial test simulation and the explicit or implicitexplicit dynamic response analysis is applied to the time integration of liquefaction problem of a buried pipe. The generalized return-mapping algorithm (Ortiz and Simo 1986) is applied to the integration algorithms of viscoplastic constitutive relations. The return mapping algorithm is, especially, crucial because the jump kinematic hardening model developed here has intersecting yield lines.

\section{Dynamic Response Analysis}

\subsection{Explicit Method}

Solution to systems of nonlinear equations is obtained as

$\mathrm{P}-\mathrm{P}^{\mathrm{init}}=\mathrm{F} \quad$ and $\quad \mathrm{P}=\sum_{\mathrm{N}} \int_{\text {vol }} \mathrm{B}^{\mathrm{T}} \sigma \mathrm{dv}$

where $\mathrm{P}$ is the internal force vector, $\mathrm{P}^{\text {init }}$ is the nodal force vector due to initial stresses, $\mathrm{F}$ is the external force vector, $\mathrm{B}^{\mathrm{T}}$ is the strain-displacement transformation matrix, $\mathrm{N}$ is the number of elements in finite element discretization, $\sigma$ is the stress at Gauss point in each element, and vol is the volume of each element. The solution to the above governing equation can be obtained by achieving the steady state response of the following dynamic equation of motion

$\mathrm{M}_{\mathrm{D}} \mathrm{a}+\mathrm{Cv}+\mathrm{P}-\mathrm{P}^{\text {init }}=\mathrm{F}$

where $M_{D}$ is the diagonalized mass matrix, $C$ is the damping matrix, which is a vector for critically damped dynamic relaxation, $\mathrm{v}$ is the velocity vector, and $\mathrm{a}$ is the acceleration vector.

Applying the central difference method to Eq. 2 and replacing the damping by the following relation
$\mathrm{C}=\alpha \mathrm{M}_{\mathrm{D}}$

the following equation can be derived;

$$
\begin{aligned}
\mathrm{q}_{\mathrm{n}+1}= & \frac{1}{1+0.5 \alpha \Delta \mathrm{t}}\left[\frac{\Delta \mathrm{t}^{2}}{\mathrm{M}_{\mathrm{D}}}\left(\mathrm{F}-\mathrm{P}+\mathrm{P}^{\mathrm{init}}\right)^{\mathrm{t}}+2 \mathrm{q}_{\mathrm{n}}\right. \\
& \left.-(1-0.5 \Delta \mathrm{t}) \mathrm{q}_{\mathrm{n}-1}\right] .
\end{aligned}
$$

Here, $\mathrm{q}_{\mathrm{n}}$ is the displacement vector at time $\mathrm{n}, \Delta \mathrm{t}$ is the time increment and $\alpha$ is the damping ratio which is the most critical value to be determined when dynamic relaxation algorithm is applied.

As dynamic response computation is based on an explicit integration scheme, it suffers from the stability problem. The condition for stable analysis can be expressed as

$\Delta \mathrm{t} \leq \beta \frac{\mathrm{l}}{\mathrm{V}_{\mathrm{c}}}$

where $\Delta \mathrm{t}$ is the time required to pass the compression wave from one node to adjacent node, $\beta$ is the stability factor $(\beta<1.0)$, and 1 is the minimum distance between the adjacent nodal point for an element and $\mathrm{V}_{\mathrm{c}}$ is the compression wave velocity of the medium.

\subsection{Implicit-Explicit Method}

The implicit method (Bathe 1996) is used to a part of the stiff structures and the explicit method without stiffness matrix is applied to other parts of soil mass. Consequently both methods are used simultaneously and the Newmark scheme is employed. The algorithms are described as follows.

$\tilde{\mathrm{q}}_{\mathrm{n}+1}=\mathrm{q}_{\mathrm{n}}+\Delta \mathrm{tv}_{\mathrm{n}}+\Delta \mathrm{t}^{2}(1-2 \beta) \mathrm{a}_{\mathrm{n}} / 2$

$\tilde{\mathrm{v}}_{\mathrm{n}+1}=\mathrm{v}_{\mathrm{n}}+\Delta \mathrm{t}(1-\gamma) \mathrm{a}_{\mathrm{n}}$

where $v_{n}$ is the velocity vector and $a_{n}$ is the acceleration vector at time $\mathrm{n}$, and $\gamma$ and $\beta$ are constants. In a time increment, the displacement is simultaneously solved from the explicit and implicit effective stiffness matrix using the Skyline solver.

$\mathrm{K}^{*}=\mathrm{M} /\left(\Delta \mathrm{t}^{2}\right)+\gamma \mathrm{C}_{\mathrm{T}} /(\Delta \mathrm{t} \beta)+\mathrm{K}_{\mathrm{T}}\left(\tilde{\mathrm{q}}_{\mathrm{n}+1}\right)($ implicit $)$

$\mathrm{K}^{*}=\mathrm{M} /\left(\Delta \mathrm{t}^{2} \beta\right)($ explicit $)$ 


$$
\mathrm{K}^{*} \Delta \mathrm{q}=\Psi
$$

where $\mathrm{M}$ is the lump mass, $\mathrm{K}_{\mathrm{T}}$ is the tangential stiffness matrix, $\mathrm{C}_{\mathrm{T}}$ is the critical damping matrix and $\Psi$ is the residual force. The residual force is evaluated by the equation.

$\Psi=\mathrm{f}_{\mathrm{n}+1}-\mathrm{Ma}_{\mathrm{n}+1}-\mathrm{P}\left(\tilde{\mathrm{q}}_{\mathrm{n}+1}, \tilde{\mathrm{v}}_{\mathrm{n}+1}\right)$

where $f_{n+1}$ is the external force vector, $P$ is the internal force vector. The displacement, velocity and acceleration of next step are calculated by the following equations.

$\mathrm{q}_{\mathrm{n}+1}=\tilde{\mathrm{q}}_{\mathrm{n}+1}+\Delta \mathrm{q}$

$\mathrm{a}_{\mathrm{n}+1}=\left(\mathrm{q}_{\mathrm{n}+1}-\tilde{\mathrm{q}}_{\mathrm{n}+1}\right) /\left(\Delta \mathrm{t}^{2} \beta\right)$

$\mathrm{v}_{\mathrm{n}+1}=\tilde{\mathrm{v}}_{\mathrm{n}+1}=\Delta \mathrm{t} \gamma \mathrm{a}_{\mathrm{n}+1}$.

\section{Elasto-Plastic Constitutive Equation}

A simplified and generalized version of mesh sizedependent softening modulus method is applied in this study. A material model for a real granular material is used with the features of nonlinear prepeak, pressure-sensitivity of the deformation, strength characteristics, non-associated flow characteristics, post-peak strain softening and strain-localization into a shear band with a specific width.

The yield function (f) and the plastic potential function $(\Phi)$ are given by

$\mathrm{f}=\alpha \mathrm{I}_{1}+\frac{\bar{\sigma}}{\mathrm{g}\left(\theta_{\mathrm{L}}\right)}=0$

$\Phi=\alpha^{\prime} \mathrm{I}_{1}+\bar{\sigma}=0$

where

$\alpha=\frac{2 \sin \phi}{\sqrt{3}(3-\sin \phi)} \alpha^{\prime}=\frac{2 \sin \psi}{\sqrt{3}(3-\sin \psi)}$

where $\mathrm{I}_{1}$ is the first invariant (positive in tension) of deviatoric stress and $\bar{\sigma}$ is the second invariant of deviatoric stress. With the Mohr-Coulomb model, $\mathrm{g}\left(\theta_{\mathrm{L}}\right)$ takes the following form

$\mathrm{g}\left(\theta_{\mathrm{L}}\right)=\frac{3-\sin \phi}{2 \sqrt{3} \cos \theta_{\mathrm{L}}-2 \sin \theta_{\mathrm{L}} \sin \phi}$

where $\phi$ is the mobilized friction angle and $\theta_{\mathrm{L}}$ is the Lode angle. The frictional hardening-softening functions expressed as follows are used.
For hardening regime;

$\alpha(\kappa)=\left(\frac{2 \sqrt{\kappa \varepsilon_{\mathrm{f}}}}{\kappa+\varepsilon_{\mathrm{f}}}\right)^{m} \alpha_{\mathrm{p}}\left(\kappa \leq \varepsilon_{\mathrm{f}}\right)$

and for softening regime;

$\alpha(\kappa)=\alpha_{\mathrm{r}}+\left(\alpha_{\mathrm{p}}-\alpha_{\mathrm{r}}\right) \exp \left\{\left(\frac{\kappa-\varepsilon_{\mathrm{f}}}{\varepsilon_{\mathrm{r}}}\right)^{2}\right\}\left(\kappa \geq \varepsilon_{\mathrm{f}}\right)$

where $\mathrm{m}, \varepsilon_{\mathrm{f}}$ and $\varepsilon_{\mathrm{r}}$ are the material constants and $\alpha_{\mathrm{p}}$ and $\alpha_{\mathrm{r}}$ are the values of $\alpha$ at the peak and residual states. Yoshida et al. (1995) indicated that shear band width was constant depending on mean particle size of soil. By introducing a strain localization parameter $\mathrm{s}$ in the following additive decomposition of total strain increment, the introduction of shear banding in the numerical analysis is achieved and given as follows

$\mathrm{d} \varepsilon_{\mathrm{ij}}=\mathrm{d} \varepsilon_{\mathrm{ij}}^{\mathrm{e}}+\mathrm{sd} \varepsilon_{\mathrm{ij}}^{\mathrm{p}}, \quad \mathrm{s}=\mathrm{F}_{\mathrm{b}} / \mathrm{F}_{\mathrm{e}}$

where $F_{b}$ is the area of a single shear band in each element, and $\mathrm{F}_{\mathrm{e}}$ is the area of an element.

The residual friction angle $\left(\phi_{\mathrm{r}}\right)$ and Poisson's ratio (v) are chosen based on the data from the test of airdried Toyoura sand. The peak friction angle $\left(\phi_{\mathrm{p}}\right)$ is estimated from the empirical relations based on the plane strain compression test and triaxial test on Toyoura sand. A dilatancy angle $\Psi$ is defined by Eqs. 22 and 23.

$\sin \psi=\frac{\sin \phi-\sin \phi_{\mathrm{r}}^{\prime}}{1-\sin \varphi \sin \phi_{\mathrm{r}}^{\prime}}$

$\phi_{\mathrm{r}}^{\prime}=\phi_{\mathrm{r}}\left[1-\beta \exp \left\{-\left(\frac{\kappa}{\varepsilon_{\mathrm{d}}}\right)^{2}\right\}\right]$

where $\beta$ and $\varepsilon_{\mathrm{d}}$ are material constants.

The jump kinematic hardening model considering the cumulative deformation by cyclic loading is developed based on modified and extended soil model of isotropic strain-hardening-softening property in order to take into account the cyclic behavior. Within bounding surface, plastic behavior is assumed and the hardening modulus is much greater compared to the plastic behavior outside the bounding surface. The hardening function is given by Eq. 24. In this equation, $\kappa^{\prime}$ is a plastic parameter and is cleared to zero at a reversal point and $\mathrm{a}_{\mathrm{f}}$ is a material constant. 


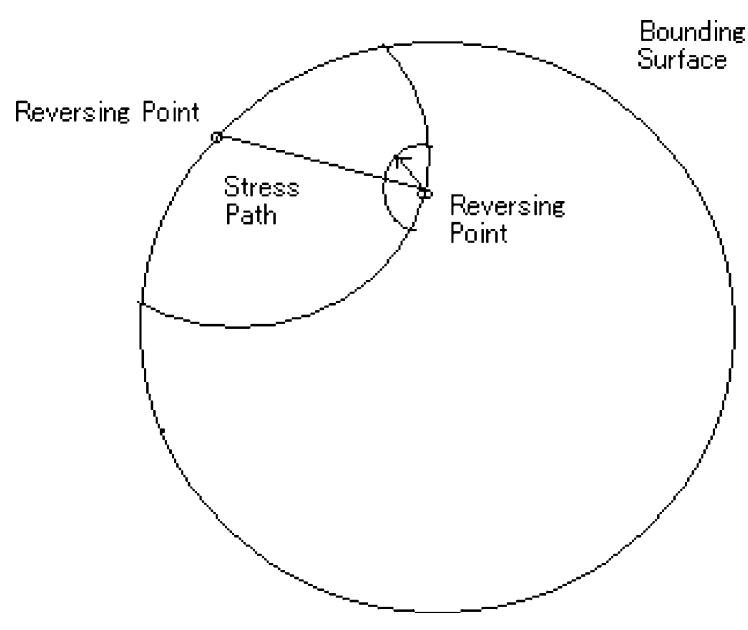

Fig. 1 Kinematic hardening model on $\pi$ plane (Mohr-Coulomb model takes irregular hexagonal shape)

The dilatancy angle $\psi^{\prime}$ is given by Eqs. 25 and 26, where $r_{f}$ in Eq. 25 is the reduction factor for dilatancy (Fig. 1).

$$
\begin{aligned}
& \alpha_{\mathrm{iy}}\left(\kappa^{\prime}\right)=\mathrm{a}_{\mathrm{f}}\left(\frac{2 \sqrt{\kappa^{\prime} \varepsilon_{\mathrm{f}}}}{\kappa^{\prime}+\varepsilon_{\mathrm{f}}}\right)^{\mathrm{m}} \alpha_{\mathrm{p}} \\
& \alpha_{\mathrm{id}}^{\prime}\left(\kappa^{\prime}\right)=\left(\alpha_{\mathrm{iy}}-\alpha_{\mathrm{p}}\right) \mathrm{r}_{\mathrm{f}} \\
& \sin \psi^{\prime}=\frac{3 \sqrt{3} \alpha_{\mathrm{id}}}{2+\sqrt{3} \alpha_{\mathrm{id}}} .
\end{aligned}
$$

\section{Viscoplastic Constitutive Model}

The constitutive equations of rate-dependent plasticity (Simo et al. 1988) originally proposed by DuvautLions are as follows.

$\sigma^{\mathrm{v}}=\eta \mathrm{C}^{\mathrm{vp}}=\sigma-\bar{\sigma}$

$\dot{\mathrm{q}}=\frac{1}{\eta}[\mathrm{q}-\overline{\mathrm{q}}]$

$$
\sigma=\sigma^{\mathrm{f}}\left(\varepsilon^{\mathrm{ir}}\right)+\sigma^{\mathrm{v}}\left(\varepsilon^{\mathrm{ir}}, \dot{\varepsilon}^{\mathrm{ir}}\right)
$$

where $\eta$ is the fluidity parameter, $\mathrm{q}$ is the internal variables, $\bar{\sigma}$ and $\overline{\mathrm{q}}$ are the rate independent solutions, $\mathrm{C}$ is the elastic modulus. Eq. 27 can be rewritten in incremental form as follows.

$$
\Delta \varepsilon^{\mathrm{ir}}=\frac{\Delta \mathrm{t}_{\mathrm{n}+1}}{\eta}\left(\sigma_{\mathrm{n}+1}-\bar{\sigma}_{\mathrm{n}+1}\right) \mathrm{C}^{-1} .
$$

After some calculation, the following equation can be obtained

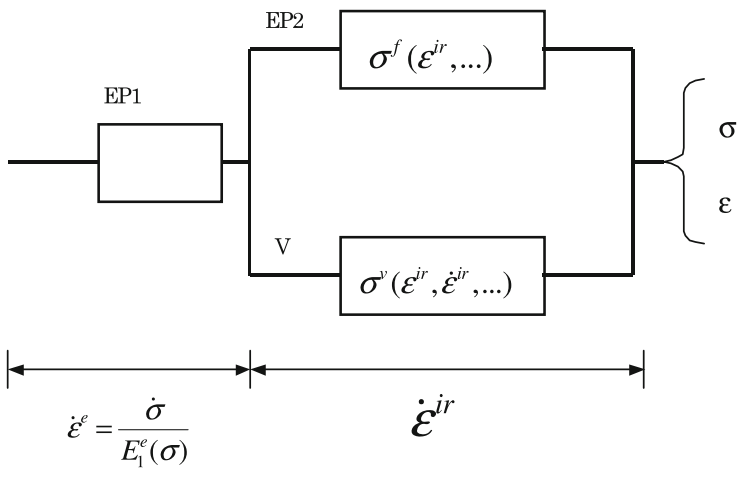

Fig. 2 Viscoplastic model

$$
\begin{aligned}
\sigma_{\mathrm{n}+1} & =\frac{\eta \mathrm{C} \Delta \varepsilon_{\mathrm{n}+1}+\eta \sigma_{\mathrm{n}}+\Delta \mathrm{t}_{\mathrm{n}+1} \bar{\sigma}_{\mathrm{n}+1}}{\Delta t_{n+1}+\eta} \\
& =\frac{\eta \sigma_{\mathrm{n}+1}^{\mathrm{trial}}+\Delta \mathrm{t}_{\mathrm{n}+1} \bar{\sigma}_{\mathrm{n}+1}}{\Delta \mathrm{t}_{\mathrm{n}+1}+\eta} .
\end{aligned}
$$

Similarly, Eq. 28 is transformed to the following equation.

$\mathrm{q}_{\mathrm{n}+1}=\frac{\mathrm{q}_{\mathrm{n}}+\Delta \mathrm{t} / \eta \overline{\mathrm{q}}_{\mathrm{n}+1}}{1+\Delta \mathrm{t} / \eta}$.

The intensive study of geomaterials indicates that the stress $\sigma$ is a unique function of irreversible strain and its rate (Tatsuoka et al. 2002). Following the framework of the three component model (Fig. 2), Tatsuoka et al. (2002) proposed the New Isotach and TESRA model

$\sigma=\sigma^{\mathrm{f}}\left(\varepsilon^{\mathrm{ir}}\right)+\sigma^{\mathrm{v}}\left(\varepsilon^{\text {ir }}, \dot{\varepsilon}^{\text {ir }}\right)$

where $\varepsilon^{\text {ir }}$ is the irreversible strain, $\dot{\varepsilon}^{\text {ir }}$ is the irreversible strain rate, $\sigma^{f}$ is the time independent (elastoplastic) stress, $\sigma^{\mathrm{v}}$ is the time dependent stress.

The New Isotach model takes the following form.

$\sigma^{\mathrm{v}}=\sigma^{\mathrm{f}} \cdot \mathrm{g}\left(\dot{\varepsilon}^{\text {ir }}\right)$

where

$\mathrm{g}\left(\dot{\varepsilon}^{\mathrm{ir}}\right)=\alpha\left[1-\exp \left\{1-\left(\frac{\dot{\varepsilon}^{\mathrm{ir}}}{\dot{\bar{\varepsilon}}_{\mathrm{r}}^{\mathrm{ir}}}\right)^{\mathrm{m}}\right\}\right]$

is a viscosity function.

From this equation, the equivalent fluidity parameter can be obtained as follows.

$\eta=\frac{\sigma^{\mathrm{f}} \alpha\left[1-\exp \left\{1-\left(\frac{\dot{\varepsilon}_{\dot{\mathrm{ir}}}^{\mathrm{ir}}}{\dot{\mathrm{r}}_{\mathrm{r}}}+1\right)^{\mathrm{m}}\right\}\right]}{\mathrm{C} \dot{\varepsilon}^{\dot{\mathrm{ir}}}}$. 
Introducing the following decay function, Tatsuoka et al. (2002) proposed the TESRA model as

$\mathrm{g}_{\text {decay }}\left(\varepsilon^{\mathrm{ir}}-\tau\right)=r_{1}^{\left(\varepsilon^{\mathrm{ir}}-\tau\right)}$.

These New Isotach and TESRA model for one dimensional viscous stress of soils are generalized to three dimensional stress by applying the relation.

$\sigma=\sigma_{\alpha \alpha} \mathrm{n}_{\alpha} \otimes \mathrm{n}_{\alpha}$

where $\mathrm{n}_{\alpha}$ is the principal direction. In this computation, the dynamic relaxation method combined with the generalized return mapping algorithm is applied to obtain the elasto-plastic stress. The obtained stress is transformed to principal stress. Then the nonlinear viscous stress in each direction and $\sigma_{\alpha \alpha}$ are computed using equivalent fluidity parameter. By applying Eq. 37, the normal three dimensional stress components can be obtained.

\section{Dynamic Progressive Failure of a Embankment Dam}

A two-dimensional model dam was prepared with a plane strain condition. The model was constructed on the shaking table using the Toyoura sand with water content $5 \%$ (Fig. 3). The sand with predetermined weight was poured on the shaking table with $5 \mathrm{~cm}$ thick, and the layer was compacted by using a vibrator to obtain the relative density of about $50 \%$. In order to measure the response of acceleration by simulated earthquake, the accelerometer was embedded in the predetermined layers at the central section.

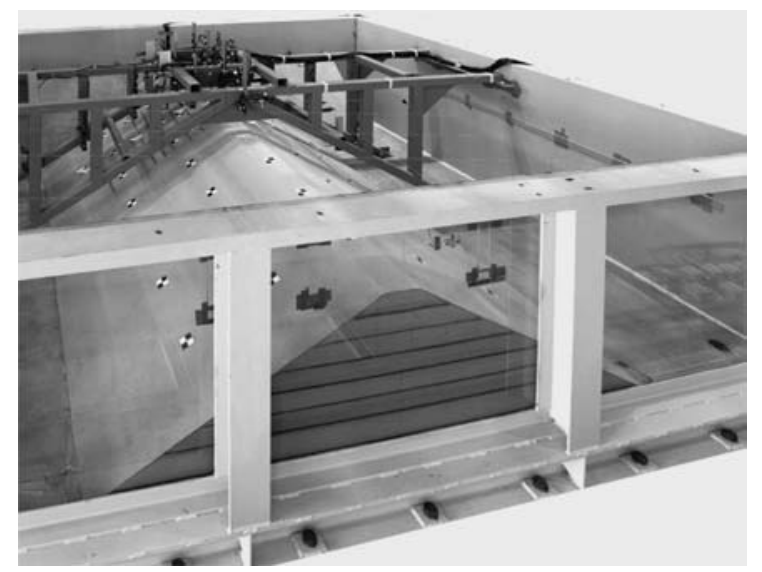

Fig. 3 Picture of model dam
The size of the model dam was $255 \mathrm{~cm}$ wide, $80 \mathrm{~cm}$ high, $255 \mathrm{~cm}$ long, and the slope was 1:1.5 (Fig. 4). The experiments were carried out at National Research Institute of Rural Engineering. The simulated earthquake has horizontal acceleration shown in Fig. 5. The observed horizontal acceleration and settlement at crest are shown in Figs. 6 and 7.

The sectional view of the model dam near the central section after test is shown in Fig. 8. The deformed shape after dynamic experiment was almost symmetric. The slip bands were circularly generated on both upstream and downstream slopes.

The elasto-plastic and viscoplastic analyses were carried out. Figure 9 shows a finite element mesh of the model dam. The material constants of Toyoura sand used for calculation are as follows: $D_{r}=50 \%$ (relative density), $\mathrm{E}=9800 \mathrm{kN} / \mathrm{m}^{2}$ (Young's modulus), $\mathrm{v}=0.3$ (Poisson's ratio), $\phi_{\mathrm{r}}=33^{\circ}$ (residual friction angle), $\varepsilon_{\mathrm{r}}=0.6, \varepsilon_{\mathrm{f}}=0.08, \mathrm{~m}=0.6$, shear band thickness $=0.3 \mathrm{~cm}$. Parameters for viscoplastic analysis are the same as of Tatsuoka et al. (2002).

The computed horizontal accelerations of the model dam from viscoplastic analyses are shown in Figs. 10, 11, 12, and 13. The maximum shear strain contour computed using viscoplastic model (constant viscosity) is shown in Fig. 14.

The computed acceleration applying the viscoplastic kinemaic hardening-softening model is identical to the experimental result but the computed acceleration by TESRA is rather erratic. TESRA is based on the experimentally obtained realistic nonlinear viscosity, so the viscosity is changing and this causes some numerical instability. We need to improve the numerical instability further, but any

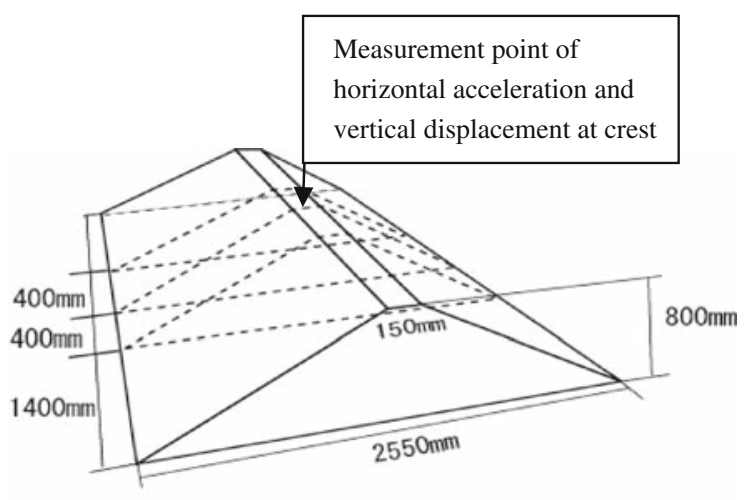

Fig. 4 Dimension of model dam 
Fig. 5 Input horizontal acceleration for model dam

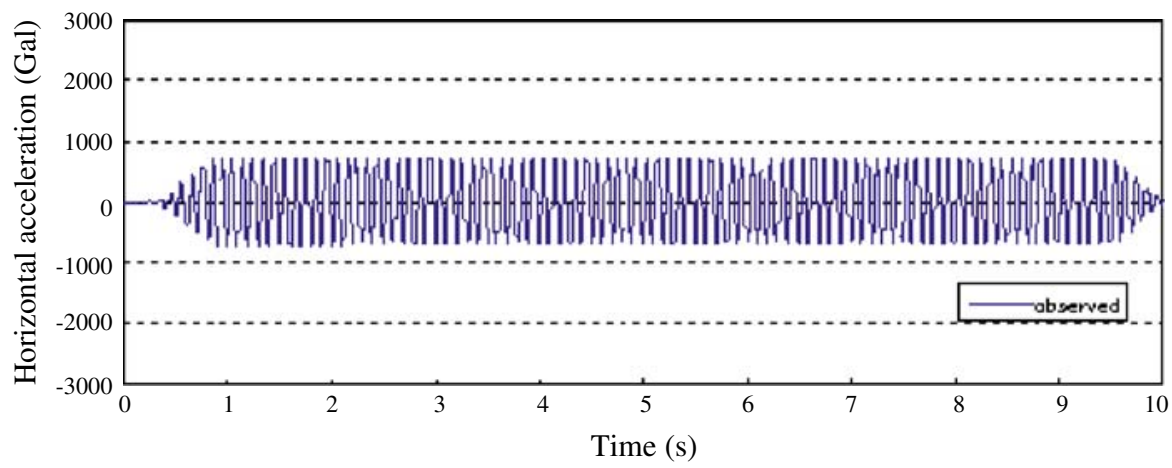

Fig. 6 Horizontal acceleration at crest by experiment

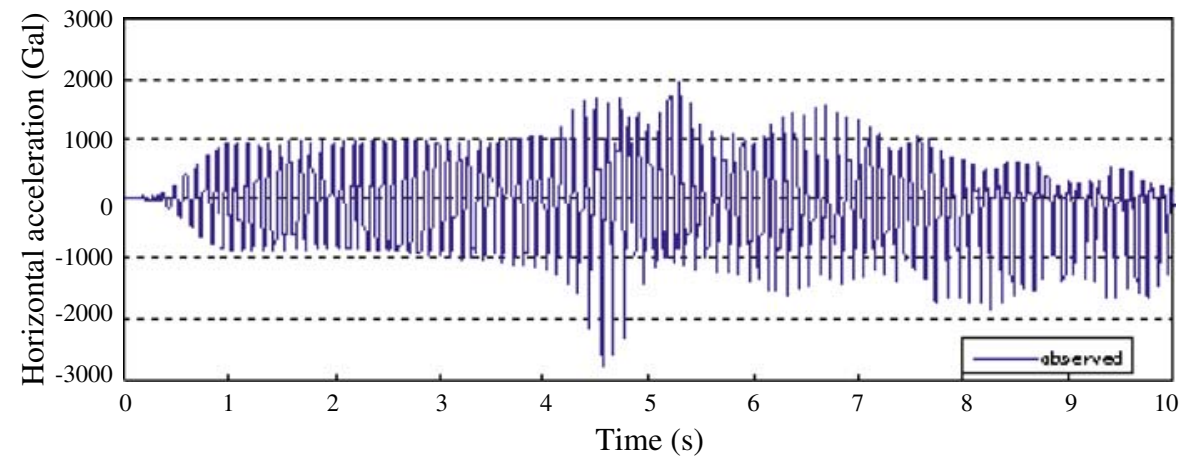

Fig. 7 Vertical displacements of dam crest

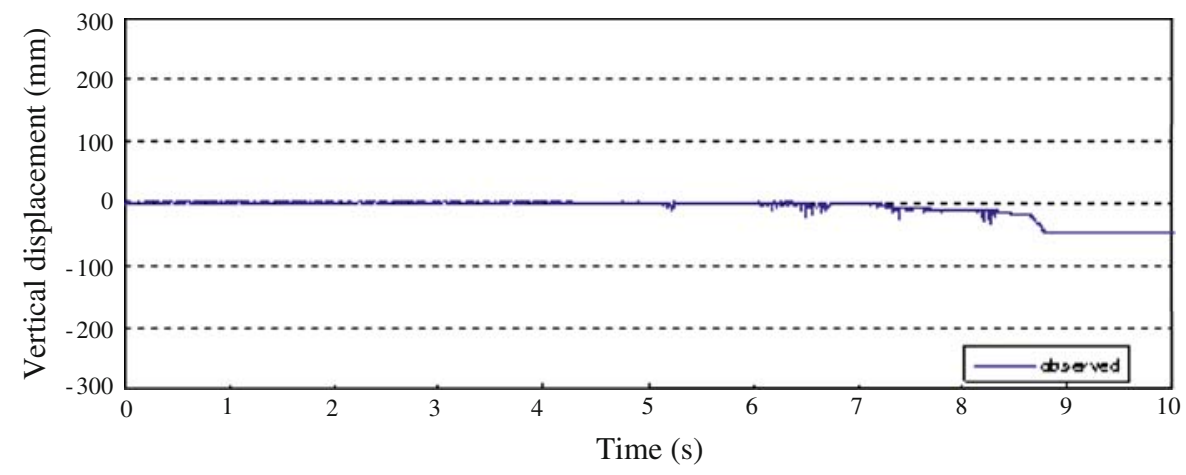

Time (s)

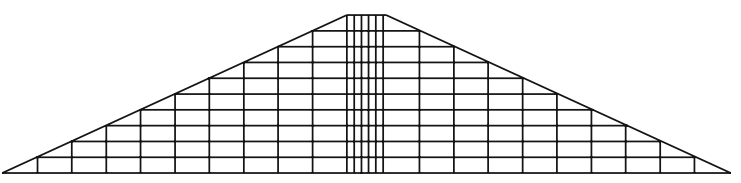

Fig. 9 Finite element mesh of model dam

Fig. 8 Sectional view after model experiment

way this model gives realistic average viscosity even for applying the more numerically stable constant viscosity model.

\section{Undrained Triaxial Test Simulation}

The simulation of triaxial tests by the finite element method using one element was carried out with 


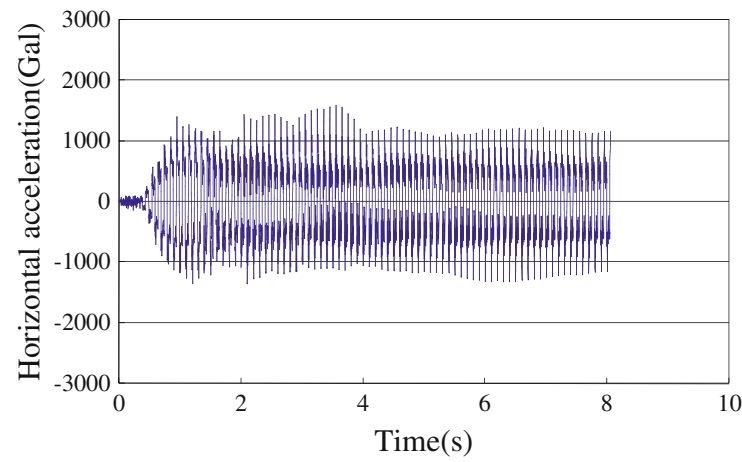

Fig. 10 Horizontal acceleration at crest by kinematic hardening viscoplastic analysis (constant viscosity: $\eta=0.000002$ $\mathrm{s} / \mathrm{kPa})$

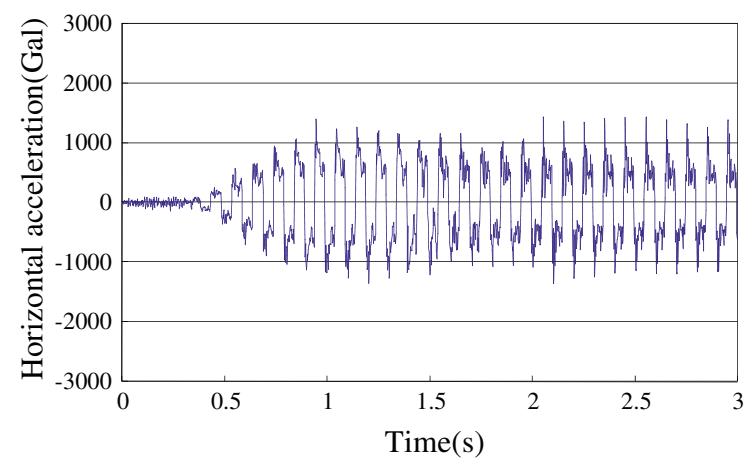

Fig. 11 Horizontal acceleration at crest by kinematic hardening viscoplastic analysis (constant viscosity: $\eta=0.000002$ $\mathrm{s} / \mathrm{kPa}$ : initial $3 \mathrm{~s}$ )

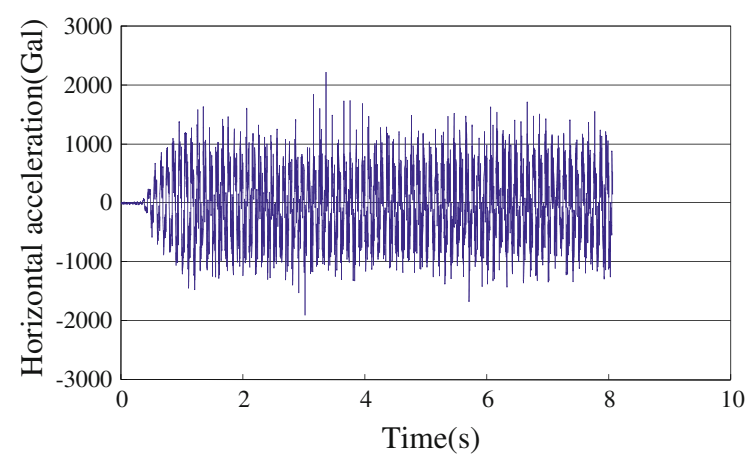

Fig. 12 Horizontal acceleration at crest by kinematic hardening viscoplastic analysis (TESRA)

kinematic hardening elasto-plastic constitutive model. The dynamic relaxation method was applied to this pseudo-static problem. The material constants of sand used for calculation are as follows: $\mathrm{D}_{\mathrm{r}}=$ $85 \%, \quad \mathrm{v}=0.3, \quad \phi_{\mathrm{r}}=33^{\circ}, \quad \varepsilon_{\mathrm{r}}=0.6, \quad \varepsilon_{\mathrm{f}}=0.08$,

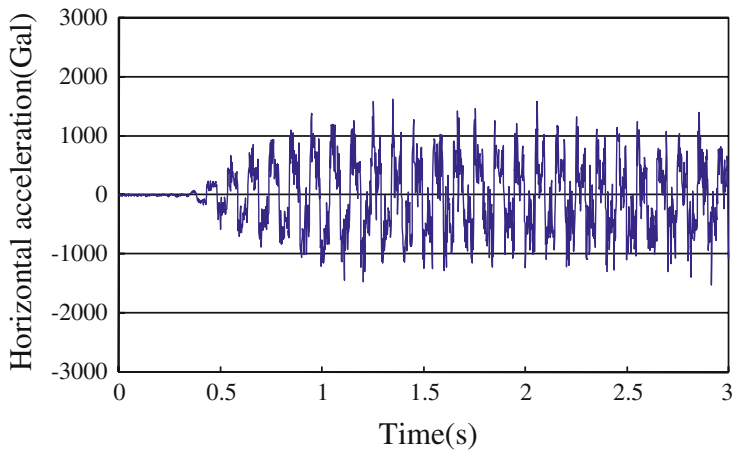

Fig. 13 Horizontal acceleration at crest by viscoplastic analysis (TESRA: initial $3 \mathrm{~s}$ )

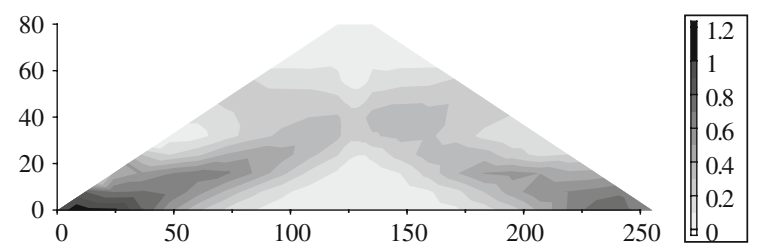

Fig. 14 Computed maximum shear strain by viscoplastic model (constant viscosity)

$\mathrm{m}=0.6$, shear band thickness $=0.3 \mathrm{~cm}$. Figure 15 shows the relations between stress difference and axial strain and Fig. 16 shows the relations between stress difference and mean stress when the applied cyclic stress is $12 \mathrm{kPa}$. Figure 17 shows the relations between stress difference and axial strain and Fig. 18 shows the relations between stress difference and mean stress at applied stress of $14 \mathrm{kPa}$. We can see that the phenomenon of cyclic mobility can be represented successfully by this kinematic hardening-softening elasto-plastic constitutive model.

\section{Dynamic Response Analysis of a Pipe Within Saturated Sand}

The finite element analyses employing the cyclic elasto-plastic and viscoplastic constitutive models were applied to dynamic analyses of a two-dimensional buried pipe problem. Figure 19 shows the finite element mesh used for the analysis. The pipe was buried within a saturated sand layer with relative density of $85 \%$. Figure 20 shows the horizontal acceleration applied to the model experiment and entered into nodes at the bottom of Fig. 19. Figure 21 


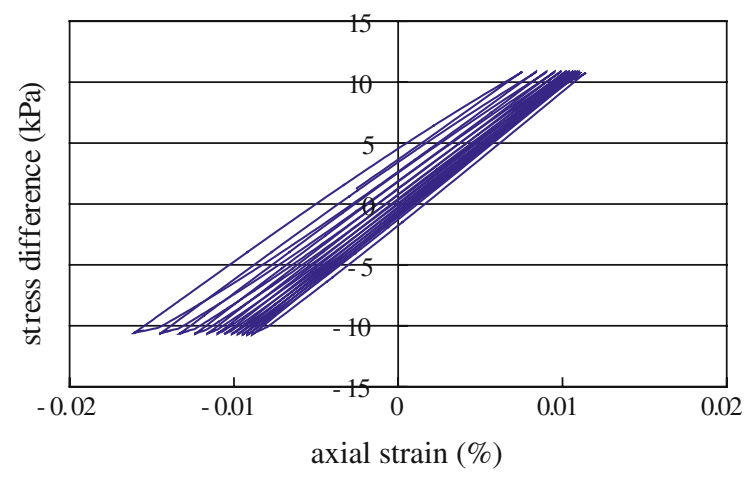

Fig. 15 Relations between stress difference and axial strain

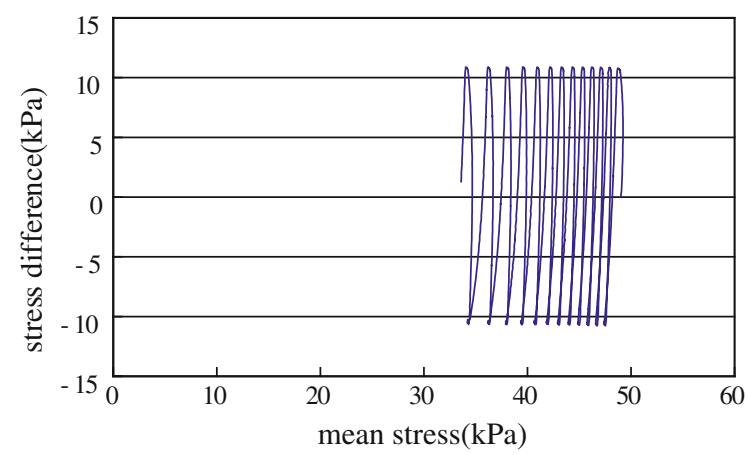

Fig. 16 Relations between mean stress and stress difference

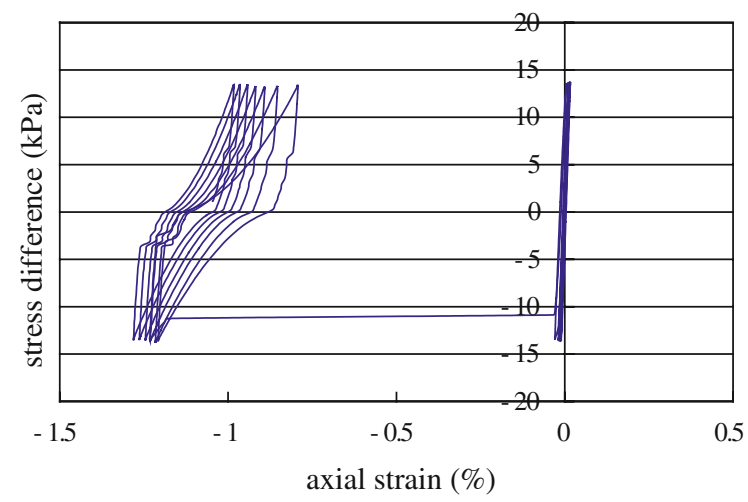

Fig. 17 Relations between stress difference and axial strain

shows observed acceleration at the center on surface of sand layer. The experiments were carried out at National Research Institute of Rural Engineering. The observed acceleration at the surface was not necessarily accurate because just after initial acceleration, the exact direction of accelerometer could not be maintained properly due to the liquefaction of

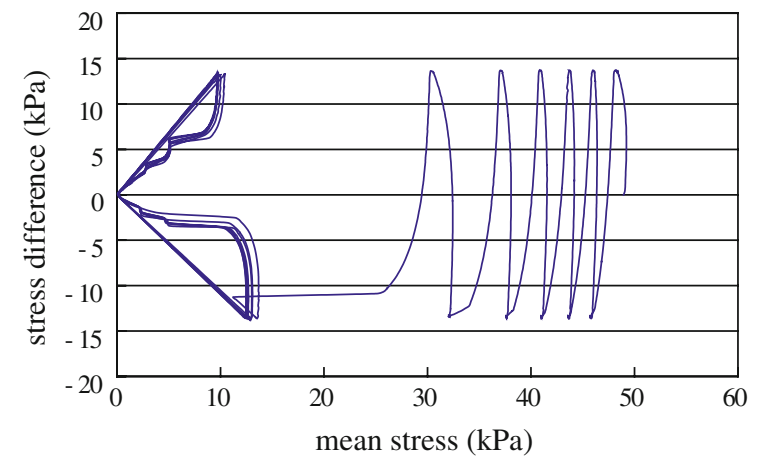

Fig. 18 Relations between undrained mean stress and stress difference

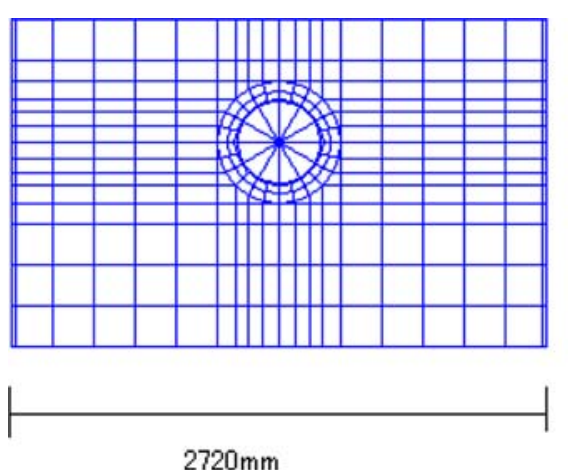

Fig. 19 Finite element mesh of buried pipe

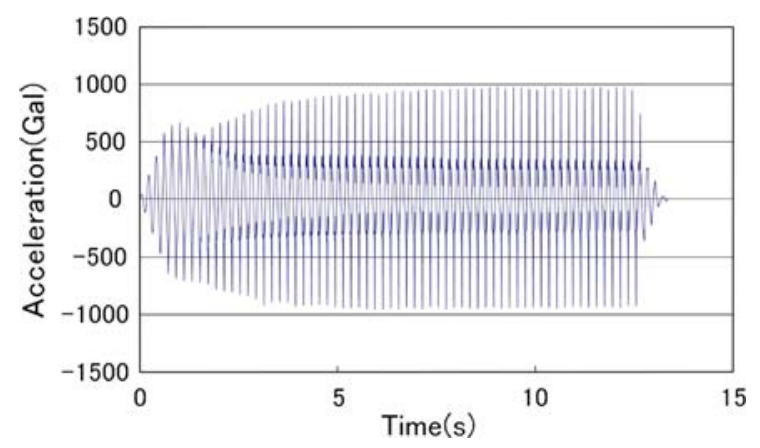

Fig. 20 Input horizontal acceleration for buried pipe

the sand layer. The observed uplift displacement is shown in Fig. 22.

At first, the calculated displacement by the endochronic theory which was combined with the elastic and perfectly plastic model, to the buried pipe is shown in Fig. 23. The densification of sand due to cyclic shear strains has been modeled with endochronic theory (Tanaka et al. 1986). The change of 


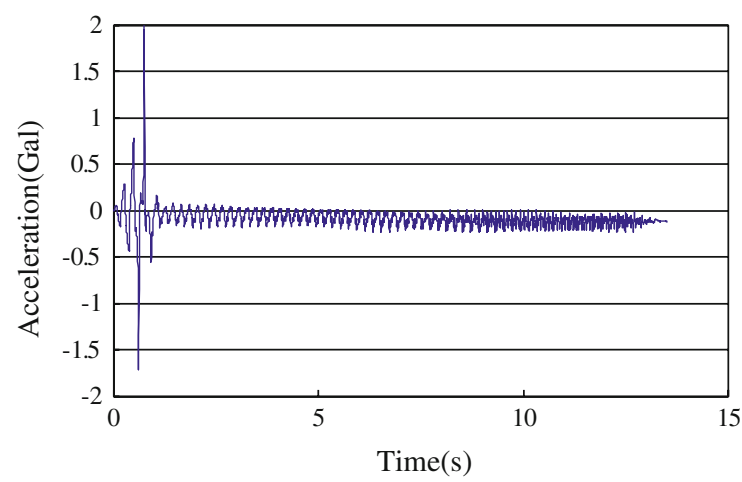

Fig. 21 Observed acceleration at the top of sand layer

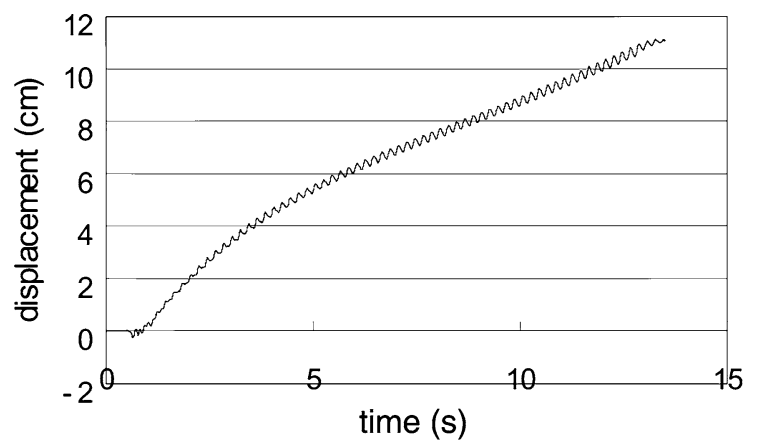

Fig. 22 Observed displacement at the top of sand layer

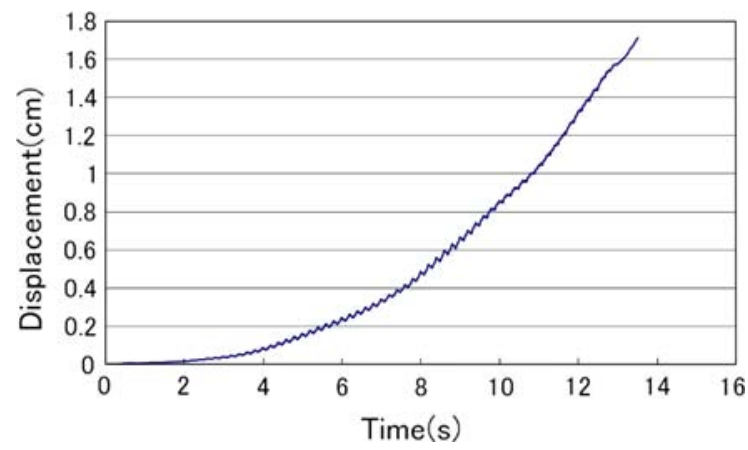

Fig. 23 Calculated displacement at the top of sand layer (endochronic theory)

volume due to densification can be described by a function of the form

$\mathrm{d} \varepsilon_{0}=\frac{\mathrm{A}}{1+\mathrm{B} \kappa} \mathrm{d} \kappa$
$\mathrm{d} \kappa=\exp \left(\alpha \mathrm{E}_{2}^{1 / 2}\right) \mathrm{d} \xi$

$$
\begin{aligned}
\mathrm{d} \xi= & \frac{1}{2}\left(\mathrm{de}_{\mathrm{ij}} \mathrm{de}_{\mathrm{ij}}\right)^{1 / 2} \\
\mathrm{de}_{\mathrm{ij}}= & \mathrm{d} \varepsilon_{\mathrm{ij}}-\frac{\mathrm{d} \varepsilon_{\mathrm{kk}}}{3} \delta_{\mathrm{ij}} \\
\mathrm{E}_{2}^{1 / 2}= & \frac{1}{\sqrt{2}}\left\{\left(\varepsilon_{11}-\varepsilon_{11_{0}}\right)^{2}+\left(\varepsilon_{22}-\varepsilon_{22_{0}}\right)^{2}\right. \\
& \left.+2\left(\varepsilon_{12}-\varepsilon_{12_{0}}\right)^{2}\right\}^{1 / 2}
\end{aligned}
$$

where $\varepsilon_{\mathrm{ij}_{0}}$ is the reference strain at strain reversal points and $\mathrm{A}, \mathrm{B}, \alpha$ are material parameters.

if $\varepsilon_{0} \leq \mathrm{K}_{\mathrm{BP}}$

$\mathrm{A}=0.237-0.374 \mathrm{D}_{\mathrm{r}}^{2}$

$\mathrm{B}=159.3-173.0 \mathrm{D}_{\mathrm{r}}^{2}$

if $\varepsilon_{0} \geq \mathrm{K}_{\mathrm{BP}}$

$\mathrm{A}=0.045+0.001 \mathrm{D}_{\mathrm{r}}-0.0446 D_{\mathrm{r}}^{2}$

$\mathrm{B}=6.12-0.61 D_{\mathrm{r}}^{2}$

where $\mathrm{K}_{\mathrm{BP}}=0.02+0.729 D_{\mathrm{r}}^{2}, \alpha=797.0$.

Next, the elasto-plastic and viscoplastic (constant viscosity) and TESRA models were applied. The material constants of sand used for the calculations are as follow: $\mathrm{D}_{\mathrm{r}}=85 \%, v=0.3, \phi_{\mathrm{r}}=3 \AA^{\circ}, \varepsilon_{\mathrm{r}}=0.6$, $\varepsilon_{\mathrm{f}}=0.1, \quad \mathrm{~m}=0.6, \quad \mathrm{a}_{\mathrm{f}}=3.0, \quad \mathrm{r}_{\mathrm{f}}=0.5, \quad \beta=0.02$, $\varepsilon_{\mathrm{d}}=2.0$ and shear band thickness $=0.3 \mathrm{~cm}$.

The calculated acceleration at the top of sand layer by the TESRA model is shown in Fig. 24. The calculated displacements by the kinematic hardening elasto-plastic constitutive model, the viscoplastic model (constant viscosity $0.00000001 \mathrm{~s} / \mathrm{kPa}$ ) and the TESRA model are shown in Fig. 25.

The agreement between the kinemaic hardeningsoftening constitutive models and experimental

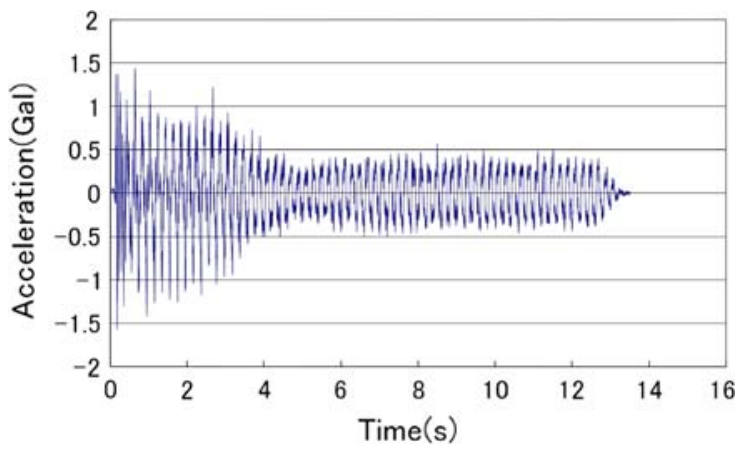

Fig. 24 Calculated acceleration at the top of sand layer (TESRA) 


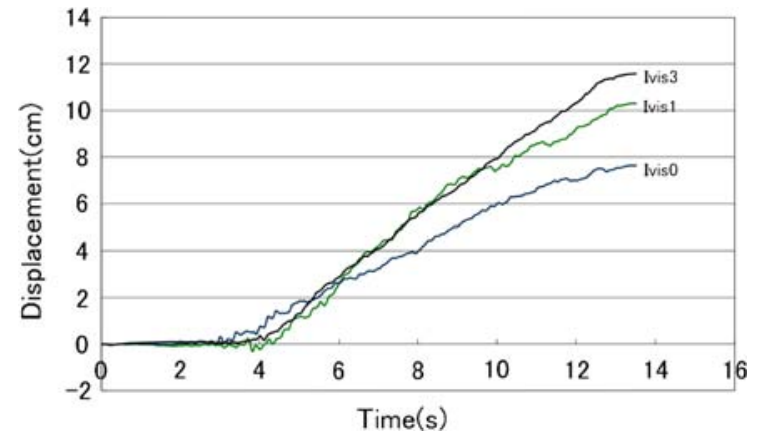

Fig. 25 Calculated displacements at the top of sand layer (elasto-plastic: Ivis0, viscoplastic (constant viscosity): Ivis1 and TESRA: Ivis3)

results is rather good and these models give more realistic displacements than endochronic theory.

\section{Conclusions}

The kinematic strain hardening-softening voscoplastic constitutive relations for geomaterials were applied to the dynamic progressive failure analysis of an embankment dam. The Duvaut-Lions viscoplastic formulation was used to solve the problem. The viscoplastic constitutive relation for sand was shown to be promising for the prediction of progressive failure of the embankment dam. The kinematic hardening model of soils was also applied to the liquefaction analysis of a buried pipe. The calculated accelerations and displacements were compared with experiments. The agreement between the kinematic hardening models and experimental results was good for prediction of the displacements, but a lesser degree of agreement was obtained for the acceleration.

Acknowledgments The authors wish to express their appreciation to Dr. Y. Mohri, National Research Institute of
Rural Engineering and Dr. M. Z. Hossain, Lecturer, Graduate School of Bioresources, Mie University for their encouragement and generous support concerning the present study. This work has been funded by the Grant-in-Aid for Scientific Research (No. 17380140) from the Ministry of Education, Sports, Science and Technology. The authors gratefully acknowledge these supports.

Open Access This article is distributed under the terms of the Creative Commons Attribution Noncommercial License which permits any noncommercial use, distribution, and reproduction in any medium, provided the original author(s) and source are credited.

\section{References}

Bathe KJ (1996) Finite element procedures. Prentice Hall, Englewood Cliffs

Ortiz M, Simo JC (1986) An analysis of a new class of integration algorithms for elasto-plastic constitutive relations, Int. J Numer Methods Eng 23:353-366

Perzyna P (1966) Fundamental problems in viscoplasticity, recent advances in Appl Mech, 9, 243-377, Academic Press, New York

Simo JC, Hughes TJR (1998) Computational inelasticity. Springer, New York

Simo JG, Kennedy JG, Govindjee S (1988) Non-smooth multisurface plasticity. Loading/unloading conditions and numerical algorithms. Int J Numer Methods Eng 26:21612185

Tanaka T, Kawamoto O (1988) Three dimensional finite element collapse analysis for foundations and slopes using dynamic relaxation. In: Proceedings of numerical methods in Geomechanics, Insbruch, 1213-1218

Tanaka T, Yasunaka M, Tani S (1986) Seismic response and liquefaction of embankments-numerical solution and shaking table tests. In: Second international symposium of numerical. methods in geomechanics, Ghent, 679-686

Tatsuoka F, Ishihara M, Di Benedetto H, Kuwano R (2002) Time-dependent shear deformation characteristics of geomaterials and simulation. Soils Found 42(2):103-129

Yoshida T, Tatsuoka F, Siddiquee MSA, Kamegai Y (1995) Shear banding in sands observed in plane strain compression, localization and bifurcation theory for soils and rocks, Balkema, 165-179 